\title{
SECOND LANGUAGE VOCABULARY ACQUISITION ENHANCED BY THE USE OF TECHNOLOGY
}

\section{Valentina Gavranović}

Singidunum University,

Belgrade, Serbia

\section{Correspondence:}

Valentina Gavranović

e-mail:

vgavranovic@singidunum.ac.rs

\begin{abstract}
:
This paper focuses on the possibilities technology offers in the area of second language teaching and learning, with the emphasis on its use for the purpose of enhancing learners' vocabulary. With the introduction of computer-assisted foreign language learning instruction, new strategies and approaches to foreign language teaching and learning have also been proposed. The aim of this work is to review effective approaches to teaching and learning vocabulary, and to analyse how these can be supported and improved by the use of various technological advances. The purpose of this paper is to promote technology-assisted vocabulary learning with the emphasis on pedagogical implications and principles guiding the use of various technological options.
\end{abstract}

\section{Keywords:}

technology-assisted learning, vocabulary acquisition, reading strategies, web tools/ apps.

\section{INTRODUCTION}

An ongoing process of change in foreign language teaching and learning paradigm has been brought about not only by the introduction of new theories and approaches in applied linguistics but also by continuous and complex social and cultural changes. The potential which technology offers has made researchers and language instructors investigate how to improve learners' language skills and enhance their language competence. These tendencies and endeavours are contributing to new developments and courses in foreign language teaching and learning.

For the last couple of decades not only has the use of technology become advantageous in promoting and improving the quality of education, but also the imperative in creating reformed curricula across the world [1]. Ever since technology was introduced in education in 1960s, it has been applied in different forms and for various purposes, but with the same goal - to facilitate and enhance the language learning process. With the advancement of technological tools, which are getting more and more sophisticated, new methods and techniques have also been introduced [2].

Technology plays a significant role in our lives, and it is an inevitable component which needs to be taken into consideration in redefining 
pedagogical principles so that the needs of the $21^{\text {st }}$ century language learner could be met. Chapelle asserts that 'technology-based language teaching and research is not a departure from applied linguistics - it is a continuation - the $21^{\text {st }}$ century version of what applied linguists do' [3].

When technology was introduced in foreign language teaching, it was primarily used to enhance students' vocabulary and grammar through the method called 'drill-and-practice', which prevailed for a long time [1]. However, the last two decades have been marked by the growing interest of researchers in the use of technology for the purpose of developing primary language skills, and the focus on second language vocabulary acquisition combined with enhancing reading skills has got a special place in applied linguistics. Comprehension-based approaches to language development considerably contributed to the research related to vocabulary acquisition and retention [4].

\section{CALL AND ITS BACKGROUND}

The second half of the $20^{\text {th }}$ century was facing the unprecedented changes in all areas of human existence which were caused by technology and its various courses of development. Education and foreign language teaching and learning were no exception. In the 1960s a new foreign language teaching concept was introduced and it relied on the use of computers in the classroom. Firstly, computer-assisted language learning (CALL) was proposed and implemented at several universities throughout the world, and it was supported by different computer programmes used for the purpose of teaching a foreign language. The most widespread types of tools and programmes were, and still are, those which support behaviourist approach to teaching, containing computer-assisted gap-fill and cloze exercises [5].

The name of CALL was officially agreed upon by a group of language instructors at TESOL convention in Toronto, in 1983 [5]. This time was marked by intensive activities related to the use of technology in applied linguistics. The possibilities which technology offered encouraged various investigations and research, and these affected practical and pedagogical implications in teaching - new curricula were designed, the market was swamped by books, programmes and coursebooks supporting and explaining the principles and ideas promoted in CALL.

The way technology was used in applied linguistics in the first decades of CALL development supported language learning rather than acquisition. However, over the years, new theories and approaches in applied linguistics were proposed, and the creation of numerous applications, programmes, multimedia tools and resources designed to facilitate language learning influenced the perception of the opposing principles of language learning and language acquisition. One of the proponents of this view was Chapelle, who claimed that CALL could promote acquisition rather than learning [5].

\section{SECOND LANGUAGE VOCABULARY ACQUISITION}

One of the primary skills a second language learner needs to develop is the knowledge of vocabulary, the skill emphasised by many researchers as a crucial feature of language learning. The process of vocabulary learning is complex and must be dealt with a systematic approach in order to help learners reach a higher level of vocabulary acquisition, retention and production. Teaching vocabulary implies having a deeper understanding of the differences between receptive and productive vocabulary, breadth and depth of vocabulary knowledge and direct teaching and contextual inference [6].

There have been different, often opposing views related to the nature of vocabulary acquisition, defended and supported by numerous investigations and research. Their main concern was to explain when a vocabulary item is considered to be learned and when to be acquired. Many linguists and researchers claimed that the best environment for vocabulary acquisition is a real one, when learners are exposed to real life situations outside the classroom, in the environment where the language is used in an authentic way, spontaneously and with no prior filtering or modifications to suit learner's needs and level of knowledge. On the other hand, formal and controlled language learning environment, as provided by the classroom and the teacher as the language instructor, is also believed to be beneficial for language learners.

In order to solve these opposing views, Krashen hypothesised the theory of comprehensible input, emphasising the importance of the input learners receive. If the classroom provides meaningful input, then this learning environment is beneficial for language learners, just like the rich resource of language material learners receive outside the classroom, in real interactions with people. Although the classroom has its limitations, it can be a resourceful environment for language learning, where students get sufficient amount of comprehensible input, 
and become equipped with necessary tools to develop their language skills further in the world outside the classroom. Among the factors which influence the efficacy of the learning environment are also the age and the language level of the learner.

Krashen claims that 'The real advantage of the informal environment is that it supplies comprehensible input. If, however, we fill our second language classrooms with input that is optimal for acquisition, it is quite possible that we can actually do better than the informal environment, at least up to the intermediate level' [7].

The last statement illustrates another complex vocabulary issue and it relates to the acquisition of vocabulary at a higher level which implies more academic register and a considerably larger set of words required for the proper understanding and use of a foreign language.

Another issue which provoked opposing opinions refers to the understanding and perception of two cognitive processes - acquisition and learning. Some authors believe that these two processes are completely opposed and separated. However, this view has been challenged by many researchers who claim that 'once learning becomes automatised, it may become acquisition' [7].

Krashen also points out that second language instructors should focus on creating learning environment which provides meaningful comprehensible input, which will, consequently, encourage acquisition. This learning environment should stimulate subconscious learning which becomes automatised and with features characteristic for language acquisition. Although conscious learning plays an important part, Krashen believes that 'conscious learning does have a role, but it is no longer the lead actor in the play', and investigates 'how we can put conscious learning, or 'grammar' in its proper place in the second language programme [7].

\section{SECOND LANGUAGE VOCABULARY ACQUISITION ENHANCED BY READING}

Due to the increased interest in vocabulary teaching and learning and the influence of comprehensionbased approaches to language development, researchers are focusing on the ways how to support the growth of learners' vocabulary [4]. There is a growing interest in the study of vocabulary acquisition and its relation to reading comprehension. Many linguistic investigations and research have pointed out that there is a close connection between reading proficiency and vocabulary knowledge.
Nagy and Herman, the proponents of the incidental vocabulary learning hypothesis, suggest that the exposure to the target language is very important if acquisition is to take place, and that it is necessary to be exposed to the aimed word 10 to 12 times [8]. Extensive reading has been promoted as an efficient way of expanding learners' vocabulary. One of the proponents of the positive impact of extensive reading on vocabulary acquisition was Krashen who claimed that learners can acquire vocabulary in this way because they are exposed to comprehensible input.

Even though theorists believed that reading, without special emphasis on vocabulary instruction, contributed to the growth of learners' vocabulary, there were no documented studies to support this claim for a long time [9]. Falcon reviews the results of the studies which investigated the impact of reading on incidental vocabulary learning, and makes the conclusion that all the cited studies confirmed the close connection between vocabulary acquisition and reading comprehension, and that there is a positive impact of the latter [10].

In order to understand a text, a leaner needs to have not only the linguistic knowledge, but also the background knowledge, developed reading strategies and motivation [8]. All these are closely interdependent and can support each other in the process of reading comprehension and vocabulary acquisition.

The focus of current research is also on developing strategies for promoting incidental vocabulary learning, and one of the suggested strategies includes the use of marginal glosses.

\section{CALL AND ITS EFFECTS ON READING COMPREHENSION AND SECOND LANGUAGE VOCABULARY ACQUISITION}

With the introduction of CALL in the 1960s, theorists believed that it supported language learning rather than acquisition. However, its developments and the view that in the learner's cognitive behaviour unconscious acquisition precedes conscious learning made many researchers reexamine and redefine these two processes. One of the proponents of the theory that CALL may promote acquisition rather than learning was Chapelle [5].

In recent years many researchers have investigated the effects of CALL on reading comprehension and second language vocabulary acquisition. The results of their studies contributed to a better understanding of this issue, and without exception they proved that 
technology-mediated language instruction can be greatly beneficial for learner's vocabulary growth.

It has been argued that computer technologies can support learning in a number of ways, one of which is the use of multimedia to enhance vocabulary development and reading comprehension. Multimedia relies on computer-based systems that use various types of content, such as text, audio, video, graphics, animation, translation and interactivity. Various studies in their conclusion stated that multimedia glosses are beneficial for students' reading comprehension skills, and since these are closely related to vocabulary acquisition, glosses are also proved to enhance vocabulary [4].

In his study Uno came to the conclusion that if learners want to memorise new words effectively and achieve retention, it is necessary to provide repeated exposure to these words. He also came to the results that previous student's experience and background knowledge play an important role in memorising even harder and longer words [11].

Relying on the view that it is easier to learn a word if it is associate with actual objects or images, Chun in his research investigated the impact of multimedia applications on vocabulary acquisition. The results of the research he conducted pointed out to the higher scores for words which were annotated with pictures and texts [12].

Starting from the premise that glossing is advantageous over non-glossed texts in enhancing incidental vocabulary learning, Makoto Yoshii in his research investigates which glosses are the most effective. However, even though the results pointed out to the positive impact of glosses on reading comprehension and incidental vocabulary learning, he could not come to conclusive results what particular types of glosses were more efficient [13].

In general, the effectiveness of glosses results from several factors. Firstly, in comparison to dictionaries they are more accessible and more accurate because the learner does not need to choose the appropriate meaning for the given context. Secondly, glosses can enhance learners' conscious learning process due to the fact that they draw learners' attention to specific words, and thus 'support the notion of "consciousness-raising" and "input-enhancement" [6]. Another advantage of using glosses is that they can encourage learners to read and reread the text from different directions, and thus support word processing with the possible result of better retention.

\section{FROM THEORY TO PRACTICE}

Taking into consideration the theoretical framework proposed earlier in the work, the author of this paper analysed reading comprehension output of 60 pre-intermediate and intermediate secondary school students. The main aim of this analysis was to find the correlation between vocabulary knowledge and the overall understanding of the texts, as well as to explain whether, and to what extent, the glosses provided in the text influenced students' overall comprehension output.

First, the students were given the task to translate a set of 10 words from English into Serbian. These words belong to a highly specialised medical register. The students had never studied these words in the formal language environment before, and the author opted for this set of words because she assumed that they were unfamiliar to students because they have a very restricted use and belong to a highly professional medical register. The results proved this assumption to be justifiable because only 5 out of 60 students knew the exact translation of a set of 3-5 words, and 11 students could provide the correct translation of one or two words. The majority of students either made wrong guesses in their translation answers or left the answer sheet empty.

Another task involved reading comprehension of a text with these words included. Due to the fact that students had had the opportunity to deal with a similar content in their mother tongue in different medical subjects, the topic was very familiar to them, and it explained the structure of the heart. All 60 students had to provide translations of these words now when they had read the text, and the results were far better than in the first task. 13 students understood the meaning of more than 6 words, and only 22 students did not understand any of these words, or they understood less than three words, and there were 25 students whose score was average - they could understand three to five of the emphasised words.

In the last task students were divided into two groups. Both groups had the same text to analyse - this time the topic was completely knew for them, they had never dealt with the topic in any other subjects before, and it referred to a description of a chronic bone disorder called Paget disease. Students were given six comprehension questions which heavily relied on understanding certain words which the author had assumed students did not know the meaning of. One group read the text with glosses which provided translation in Serbian for these words, and the other group read the text 
without any explanation. The results were rather different. The group which had the glosses outperformed the other group in this comprehension task - 12 students could understand four or more questions, and 7 of them did not understand any of these questions or they understood only one or two questions, and11 students had the average score of three correct answers.

The group which did not have any help did far worse in this task - only 4 students could understand four or more questions, and 19 of them did not understand any of these questions or they could understand only one or two of the questions, and 7 students had the average score of three correct answers.

Furthermore, those students who had the text with glosses did the vocabulary test next class - they were given the same text without glosses, and the aimed words were underlined. Their task was to provide translation for these words. The results were quite satisfactory - 6 students could remember the meaning of four or more words, and 15 of them did not understand any of these words or they could understand one or two words, and 9 students had the average score of three correct answers.

The results of the performed tasks support the view that reading comprehension largely depends on vocabulary knowledge. They also emphasise the importance of comprehensible input and background knowledge of the reading content. Students could understand the meaning of words completely new for them in English because they had solid knowledge in the specified topic, and they used the strategy of inference in order to understand the meaning of the text. On the other hand, the same group of students could not comprehend the meaning of the analysed text which contained content unfamiliar to them. It means they did not have much to rely on in deducing the meaning of the words themselves, nor could they comprehend the meaning of those parts of the text which contained these key words. The results also point out to the importance of organising instructed lessons, with a meaningful comprehensible input which will facilitate students' reading comprehension. Those students who had help in the form of glosses could much more successfully perform the given task.

\section{PEDAGOGICAL IMPLICATIONS}

The studies reviewed in this paper and the results of various investigations and research presented in the previous chapters imply that it is very important to understand the principles of second language vocabulary acquisition and how it can be enhanced by technology. When planning to introduce technological tools or applications, every language instructor needs to be aware of the pedagogical implications.

In the first place, the language instructor should be well aware of students' needs, interests, age and the level of their language proficiency. This knowledge can greatly help teachers select the type of texts that best suit their learners. There are several criteria for the selection. First of all, the text should be meaningful for students, and include the content which is relevant for their needs and interests. In order to enhance their reading comprehension skills and allow subconscious vocabulary acquisition, the language instructor needs to select those texts which contain a meaningful comprehensible input, with sufficient amount of contextual hints and clues which will facilitate the process of learning.

The accompanying tasks should be devised in such a way that learners focus attention not only to the overall reading comprehension but also to the lexical level, and, thus, consciously, through the use of the aimed words subconsciously acquire these words [10]. These tasks should also contain the target vocabulary which is frequently used in different contexts and environments so that the criterion of exposure is satisfied.

If the text does not contain context which is sufficient for the proper understanding of the target vocabulary, material developers and language instructors have at their disposal various technological tools and applications which can aid students' language learning process. Among these different kinds glosses have proved to be very helpful and purposeful in developing reading strategies and second language vocabulary acquisition. Language learners, not only at advanced but also at lower levels of proficiency, can benefit from reading authentic texts if these are supported by meaningful explanations which do not distract the natural speed of reading.

\section{CONCLUSION}

Approaches to foreign language teaching, their underlying principles and pedagogical implications stemming from them have been modified in recent decades due to the advancement of computer technology and development of various tools and applications. The new trends in ELT show that computer-assisted language learning is gaining in popularity, and numerous studies have proved that the use of technology, if properly applied, can be rather beneficial for language learners. 
In this work we have examined the effects technology-mediated instructions can have on reading comprehension and second language vocabulary acquisition. The results of various studies reviewed in this paper, as well as the results of the analysis of student's reading comprehension related to medical texts show that technology can greatly help learners understand reading demands. We have also examined the correlation between second language acquisition and reading comprehension. In order to enhance learners' vocabulary both intentional and incidental learning are valuable methods, and various computer-assisted techniques can contribute to a more effective learning process. Different types of glosses which accompany reading texts have been proved to be rather useful, especially in cases when the context does not provide a meaningful input for the interference of the meaning. With the use of glosses, especially of the multimodal type, learners can be encouraged to learn with more confidence within their zone of proximal development.

Although it has been proved that technology-mediated foreign language learning improves reading comprehension skills and contributes to the expansion of vocabulary, applied linguistics is facing the challenge of providing more studies and research related to vocabulary retention and production.

\section{REFERENCES}

[1] L. Li, New Technologies and Language Learning, London: Palgrave Macmillan Education, 2017.

[2] H. Reinders, G. Stockwell, "Computer-assisted second language acquisition," in The Routledge Handbook of Instructed Second Language Acquisition, Loewen, S. and Sato, M. New York: Routledge, pp. 361-365, 2017.
[3] C. Chapelle, "Technology and Second Language Acquisition," Annual Review of Applied Linguistics, vol 27, pp. 98-114, 2007.

[4] A. I. Constantinescu, "Using Technology to Assist in Vocabulary Acquisition and Reading Comprehension," The Internet TESL Journal, 2007.

[5] O. B.Villalobos, "Reflections on the connection between computer-assisted language learning and second language acquisition," Innovaciones Educativas, vol. 19, 2012.

[6] N. Fahimipour, M. Hashemian. "The Effect of Lexical Glossing Types on Reading and Listening Skills of Iranian EFL Learners," Journal of Language Teaching and Research, vol. 4, no. 1, pp. 192-199, January 2013.

[7] S. D. Krashen, Principles and Practice in Second Language Acquisition, Pergamon Press Inc, 1982.

[8] J. Coady, "L2 Vocabulary Acquisition Through Extensive Reading," Second Language Vocabulary Acquisition: A Rationale for pedagogy, J. Coady and T. Huckin, Cambridge: Cambridge University Press, pp. 225-237, 1997.

[9] P. A. Herman, R. C. Anderson. P. D. Pearson, W. E. Nagy, "Incidental acquisition of word meaning from expositions with varied text features," Reading Research Quarterly, vol. 22, no. 3, pp. 263-284, 1987.

[10] R. R. Falcon, "Incidental Vocabulary Learning in Second Language Acquisition: A Literature Review," Profile, vol. 17, no. 1, pp. 157-166, 2015.

[11] T. Ono, "Vocabulary Learning Through Computer Assisted Language Learning," Hitotsubashi Journal of Arts and Sciences vol. 58, pp.67-72, 2017.

[12] D. M. Chun, J. L. Plass (1996), "Effects of multimedia annotations on vocabulary acquisition," The Modern Language Journal, vol. 80, pp. 183-197, 1996.

[13] M. Yoshii, "L1 and Ls Glosses: Their Effects on Incidental Vocabulary Learning," Language Learning \& Technology, vol. 10, no. 3. pp. 85-101, 2006. 